\title{
Genetic transformation of Fusarium avenaceum by Agrobacterium tumefaciens mediated transformation and the development of a USER-Brick vector construction system
}

Lisette Quaade Sørensen ${ }^{1}$, Erik Lysøe ${ }^{3}$, Jesper Erup Larsen', Paiman Khorsand-Jamal', Kristian Fog Nielsen ${ }^{2}$ and Rasmus John Normand Frandsen ${ }^{1 *}$

\begin{abstract}
Background: The plant pathogenic and saprophytic fungus Fusarium avenaceum causes considerable in-field and post-field losses worldwide due to its infections of a wide range of different crops. Despite its significant impact on the profitability of agriculture production and a desire to characterize the infection process at the molecular biological level, no genetic transformation protocol has yet been established for F. avenaceum. In the current study, it is shown that F. avenaceum can be efficiently transformed by Agrobacterium tumefaciens mediated transformation. In addition, an efficient and versatile single step vector construction strategy relying on Uracil Specific Excision Reagent (USER) Fusion cloning, is developed.
\end{abstract}

Results: The new vector construction system, termed USER-Brick, is based on a limited number of PCR amplified vector fragments (core USER-Bricks) which are combined with PCR generated fragments from the gene of interest. The system was found to have an assembly efficiency of $97 \%$ with up to six DNA fragments, based on the construction of 55 vectors targeting different polyketide synthase (PKS) and PKS associated transcription factor encoding genes in $F$. avenaceum. Subsequently, the $\triangle F a P K S 3$ vector was used for optimizing A. tumefaciens mediated transformation (ATMT) of $F$. avenaceum with respect to six variables. Acetosyringone concentration, co-culturing time, co-culturing temperature and fungal inoculum were found to significantly impact the transformation frequency. Following optimization, an average of 140 transformants per $10^{6}$ macroconidia was obtained in experiments aimed at introducing targeted genome modifications. Targeted deletion of FaPKS6 (FA08709.2) in F. avenaceum showed that this gene is essential for biosynthesis of the polyketide/nonribosomal compound fusaristatin A.

Conclusion: The new USER-Brick system is highly versatile by allowing for the reuse of a common set of building blocks to accommodate seven different types of genome modifications. New USER-Bricks with additional functionality can easily be added to the system by future users. The optimized protocol for ATMT of $F$. avenaceum represents the first reported targeted genome modification by double homologous recombination of this plant pathogen and will allow for future characterization of this fungus. Functional linkage of FaPKS6 to the production of the mycotoxin fusaristatin A serves as a first testimony to this.

Keywords: Single step cloning, ATMT, Agrobacterium tumefaciens mediated transformation, Fusarium avenaceum, USER-Brick, Genome modification, Transformation, Fusaristatin, FaPKS6, Mycotoxin, LC-MS, MS-MS, Polyketide,

Nonribosomal peptide

\footnotetext{
* Correspondence: rasf@bio.dtu.dk

'Eukaryotic Molecular Cell Biology Group, Department of Systems Biology,

The Technical University of Denmark, Søltofts Plads building 223, DK-2800 Kgs., Lyngby, Denmark

Full list of author information is available at the end of the article
}

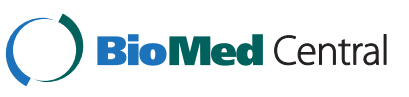

(c) 2014 Sørensen et al.; licensee BioMed Central Ltd. This is an Open Access article distributed under the terms of the Creative Commons Attribution License (http://creativecommons.org/licenses/by/4.0), which permits unrestricted use, distribution, and reproduction in any medium, provided the original work is properly credited. The Creative Commons Public Domain Dedication waiver (http://creativecommons.org/publicdomain/zero/1.0/) applies to the data made available in this article, unless otherwise stated. 


\section{Background}

The plant pathogenic fungus Fusarium avenaceum displays a wide host range and causes diseases such as root rot and ear blight of cereals [1]. The financial losses are mainly due to crown rot and head blight of wheat and the accompanying contamination of the harvested grains with mycotoxins [2]. In addition, to the direct in field effects on harvest yields, this species is also responsible for post-harvest rot of many crops, such as swede turnip [3], apple [4], broccoli [5] and potato tubers [6]. In temperate regions of the world, such as Scandinavia, Russia and Canada, F. avenaceum has in several reports been found to be the dominant species in connection with head blight. However, in recent years an increasing prevalence in warmer regions, throughout the world, has also been reported [2,7]. During infections and in post-harvest situations $F$. avenaceum has been reported to produce various bioactive secondary metabolites, including antibiotic Y, chlamydosporol, aurofusarin, enniatins, and the mycotoxins fusarin C, 2-amino-14,16-dimethyloctadecan-3-ol, and moniliformin $[2,8]$.

In spite of its significant impact on agricultural production only a few studies have aimed at elucidating the molecular genetic basis of this species' broad host range, large geographical distribution and potential for biosynthesis of secondary metabolites [9]. One of the major hurdles for such studies in this species, and many others is the lack of reliable genetic transformation protocols and a basic toolbox for performing targeted genome modifications. The Agrobacterium tumefaciens mediated transformation (ATMT) technique has proven capable of transforming a wide range of different fungal species [10].

The current study concerns the establishment of an efficient transformation protocol for $F$. avenaceum, via ATMT, and the development of a new strategy for single step construction of binary vectors compatible with ATMT of filamentous fungi. The new USER-Brick vector system is compatible with two different popular vector backbone series, pAg1 and ppPK2/pPZP-201BK, and allows for high throughput vector construction. The system provides a versatile toolbox for the construction of plasmids that can be used to address typically posed biological questions, such as 1) what effect will deletion or 2) overexpression of a given gene have on the phenotype, 3) when, and where in the mycelium is the gene in question expressed, and 4) the subcellular localization of a given protein. The system was tested by performing targeted modification (deletion and overexpression) of fourteen different loci in the $F$. avenaceum genome, and by overexpression of 30 PKS associated transcription factor encoding genes from random loci in the $F$. avenaceum genome.

\section{Methods}

\section{Organisms}

E. coli DH5 $\alpha$ was used in connection with USER cloning experiments. Chemically competent $E$. coli cells were produced as described in [11]. Agrobacterium tumefaciens LBA4404 was used for ATMT experiments. Transformation and cultivation of $E$. coli and A. tumefaciens was performed as described in [12]. F. avenaceum IBT41708 and Fusarium graminearum $\mathrm{PH}-1$ were obtained from the fungal culture collection at The Technical University of Denmark. Macroconidia for both fungal species were produced using sporulation medium as described in [13]. For the selective steps of ATMT the fungi were cultured at $26^{\circ} \mathrm{C}$ in darkness on Defined Fusarium Medium (DFM): $12.5 \mathrm{~g} / \mathrm{L}$ glucose, $1.32 \mathrm{~g} / \mathrm{L}$ L-asparagine, $0.517 \mathrm{~g} / \mathrm{L} \mathrm{MgSO}_{4}, 1.524 \mathrm{~g} / \mathrm{L} \mathrm{KH}_{2} \mathrm{PO}_{4}, 0.746 \mathrm{~g} / \mathrm{L}$ $\mathrm{KCl}, 0.04 \mathrm{mg} / \mathrm{L} \mathrm{Na}_{2} \mathrm{~B}_{4} \mathrm{O}_{7}, 0.4 \mathrm{mg} / \mathrm{L} \mathrm{CuSO}_{4}, 1.2 \mathrm{mg} / \mathrm{L}$ $\mathrm{FeSO}_{4}, 0.7 \mathrm{mg} / \mathrm{L} \mathrm{MnSO}_{4}, 0.8 \mathrm{mg} / \mathrm{L} \mathrm{NaMoO}_{2}, 10 \mathrm{mg} / \mathrm{L}$ $\mathrm{ZnSO}_{4}$.

\section{Amplification of USER-Bricks}

The current core USER-Bricks includes vector backbones, selection markers, promoters and fluorescent markers as shown in Figure 1 top panel. PCR reactions were performed using X7 [14] or Pfu Turbo Cx Hotstart DNA polymerase (Agilent Technologies) in $50 \mu \mathrm{l}$ reactions with Phusion HF buffer (New England Biolabs). Core USER-Bricks were amplified from purified plasmid DNA, $1 \mathrm{ng} / 50 \mu \mathrm{l}$ reaction, using 2-deoxyuridine containing primers from Integrated DNA Technologies (Leuven, Belgium) as specified in Figure 2. Genomic inserts (Figure 1, centre panel) unique for the individual target were amplified from purified $F$. avenaceum genomic DNA, $10 \mathrm{ng} / 50 \mu \mathrm{l}$ reactions, using the gene specific primers listed in Additional file 1: Tables S1 and S2, with the relevant overhangs specified in Figure 3. For targeted integration 1500 bp long homologous recombination sequences were used, and in the case of expression from random loci the coding sequence of the gene plus 500 bp downstream were amplified. A G-Storm GS2 thermal cycler (G-Storm, Somerton, UK) was used for PCR, with the following program: $98^{\circ} \mathrm{C}$ for $10 \mathrm{~min}$, 35 cycles $\left(98^{\circ} \mathrm{C}\right.$ for $20 \mathrm{sec}, 60^{\circ} \mathrm{C}$ for $20 \mathrm{sec}, 72^{\circ} \mathrm{C}$ for $2 \mathrm{~min}), 72^{\circ} \mathrm{C}$ for $5 \mathrm{~min}$. The PCR amplicons were gel purified using the illustra GFX PCR DNA and Gel Band Purification Kit (GE Healthcare), to eliminate the plasmid and genomic DNA that had served as the templates during the PCR reactions.

\section{Construction of plasmids from USER-Bricks}

The USER-Bricks and 'gene specific fragments' needed for the different types of experiments are described in Figure 1. For USER cloning reactions $1 \mu \mathrm{l}$ of the needed purified USER-Bricks and $2 \mu \mathrm{l}$ of the required gene specific inserts 


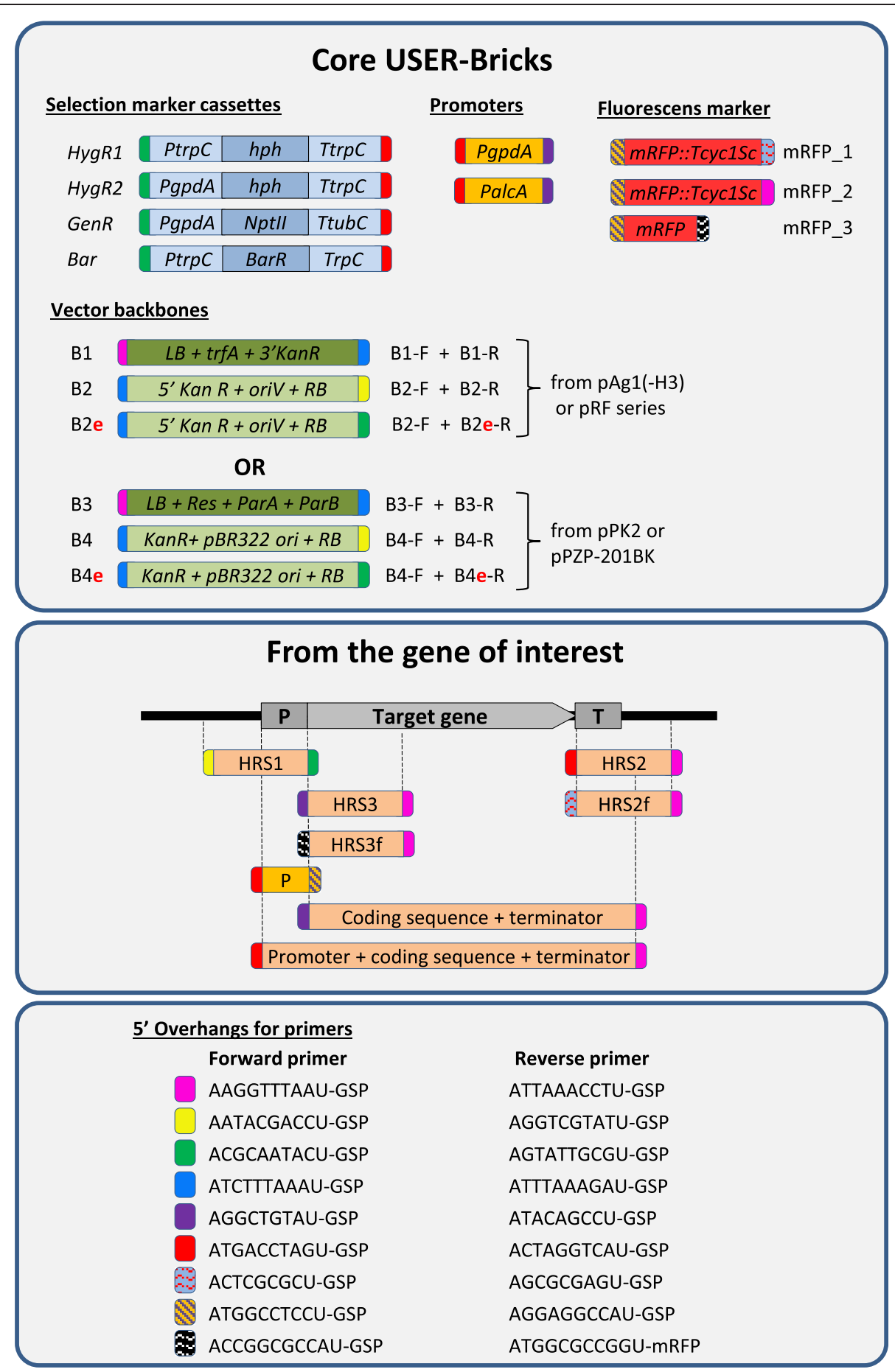

Figure 1 The different DNA fragments (=bricks) in the USER-Brick vector system. The ends of the Bricks are colour coded based on which overhangs that are compatible for fusion. Top panel: The core USER-Brick includes backbones, selection markers, promoters and fluorescent marker fragments. Centre panel: The placement of the different types of PCR amplicons in relation to the gene of interest. Bottom panel: Sequences of the $5^{\prime}$ overhang found on the primers for amplifying the different USER-Bricks in the two panels above.

were mixed with 1.2 units of 'USER enzyme mix' (New England Biolabs) and 10xTaq DNA polymerase buffer (Sigma-Aldrich) to a final concentration of $1 \mathrm{x}$, in a total volume of $12 \mu$ l. The reactions were incubated for $25 \mathrm{~min}$ at $37^{\circ} \mathrm{C}$ and then for 25 min at $25^{\circ} \mathrm{C}$ using a thermal cycler. The entire reaction volume was used for transformation of $50 \mu \mathrm{l}$ chemically competent $E$. coli DH5 $\alpha$ cells, as described in [12]. Ten of the resulting transformants were 


\begin{tabular}{|c|c|c|c|c|c|}
\hline Name: & Sequence ( $5^{\prime}$ to $\left.3^{\prime}\right)$ & Purpose & $\begin{array}{l}\text { Tem- } \\
\text { plate }\end{array}$ & \begin{tabular}{|c|} 
PCR \\
product
\end{tabular} & Compatible overhangs \\
\hline \multicolumn{6}{|c|}{ Backbone USER-Bricks based on pAg1-H3/pRF-HU2 plasmids } \\
\hline B1-F & AAGGTTTAAUTCACTGGCCGTCGTTTTA & Generic & A & \multirow{2}{*}{$2165 b p$} & HRS2-R, CDS-R \\
\hline $\mathrm{B} 1-\mathrm{R}$ & ATTTAAAGAUCCGCGCGAGC & Generic & A & & B2-F \\
\hline B2-F & ATCTTTAAAUGGAGTGTCTTCTTCCCA & Generic & A & \multirow{2}{*}{$1658 \mathrm{bp}$} & B1-R \\
\hline$\square \mathrm{B} 2-\mathrm{R}$ & AATACGACCUTCGTGACTCCCTTAATTCT & Generic & A & & HRS1-F \\
\hline B2e-R & AGTATTGCGUTCGTGACTCCCTTAATTCT & Ectopic express. & A & $1658 \mathrm{bp}$ & Marker-F \\
\hline \multicolumn{6}{|c|}{ Backbone USER-Bricks based on ppPK2 or pPZP-201BK } \\
\hline B3-F & AAGGTTTAAUCGTTTCCCGCCTTCAGTTTAAA & Generic & B & \multirow{2}{*}{$3096 \mathrm{bp}$} & HRS2-R \\
\hline B3-R & AGCGGCTAAUCAAGGCTTCACCC & Generic & B & & B2-F \\
\hline B4-F & ATTAGCCGCUACAAGATCGTAAAGA & Generic & B & \multirow{2}{*}{$2937 \mathrm{bp}$} & B1-R \\
\hline$\square$ B4-R & AATACGACCUTGTGTTATTAAGTTGTCTAAGCGTCA & Generic & B & & HRS1-F \\
\hline B4e-R & AGTATTGCGUTGTGTTATTAAGTTGTCTAAGCGTCA & Ectopic express. & B & $2937 b p$ & Marker-F \\
\hline \multicolumn{6}{|c|}{ Dominant antibiotic markers for fungal selection: } \\
\hline$\square$ HygR1-F & ACGCAATACUAGTCGGGGGATCCTCTAG & \multirow{2}{*}{\begin{tabular}{|l} 
Hygromycin marker 1 \\
PtrpC:hph:TtrpC
\end{tabular}} & \multirow{2}{*}{$A, C$} & \multirow{2}{*}{$2480 \mathrm{bp}$} & B2-R, B4-R \\
\hline HygR1-R & ACTAGGTCAUGGGCCCATCGATGATCAG & & & & HRS2-F, CDS-R, promoter-F \\
\hline$\square$ HygR2-F & ACGCAATACUATCTTTCGACACTGAAATACGT & \multirow{2}{*}{$\begin{array}{l}\text { Hygromycin marker } 2 \\
\text { PpgdA:hph:TtrpC }\end{array}$} & \multirow{2}{*}{$D$} & \multirow{2}{*}{$3989 \mathrm{bp}$} & B2-R, B4-R \\
\hline HygR2-R & ACTAGGTCAUTCGAGTGGAGATGTGGAGTGGG & & & & HRS2-F, CDS-R, promoter-F \\
\hline$\square$ GenR-F & ACGCAATACUCATGCAACATGCATGTACTGTCTGAT & \multirow{2}{*}{$\begin{array}{l}\text { Geneticin marker } \\
\text { PgpdA:NPTII:NcTtubC }\end{array}$} & \multirow{2}{*}{ E } & \multirow{2}{*}{$1440 \mathrm{bp}$} & B2-R, B4-R \\
\hline GenR-R & ACTAGGTCAUCGCGGCTTCGAATCGTGG & & & & HRS2-F, CDS-R, promoter-F \\
\hline$\square$ Bar-F & ACGCAATACUAAGAAGGATTACCTCTAAACAAGTG & \multirow{2}{*}{\begin{tabular}{|l|} 
Bar resistance \\
PtrpC:barR:TtrpC
\end{tabular}} & \multirow{2}{*}{$\mathrm{F}$} & \multirow{2}{*}{$1677 \mathrm{bp}$} & B2-R, B4-R \\
\hline Bar-R & ACTAGGTCAUTCGACAGAAGATGATATTGAAGGAGC & & & & HRS2-F, CDS-R, promoter-F \\
\hline \multicolumn{6}{|l|}{ Promoters: } \\
\hline PgpdA-F & ATGACCTAGUGCCAGCCCGAATTCCCTTGTATC & \multirow{2}{*}{ Constitutive } & \multirow{2}{*}{ G } & \multirow{2}{*}{$2320 \mathrm{bp}$} & Marker-R \\
\hline PgpdA-R & ATACAGCCUGGGTGATGTCTGCTCAAGCGGGG & & & & CDS-F \\
\hline PalcA-F & ATGACCTAGUCTCCCCGATGACATACAGGAGG & \multirow{2}{*}{ Inducible } & \multirow{2}{*}{ G } & \multirow{2}{*}{$853 \mathrm{bp}$} & Marker-R \\
\hline \begin{tabular}{|l|} 
PalcA -R \\
\end{tabular} & ATACAGCCUTTGAGGCGAGGTGATAGGATTG & & & & CDS-F \\
\hline \multicolumn{6}{|c|}{ Transcriptional reporter: } \\
\hline mRFP-F & ATGGCCTCCUCCGAGGACGTCATCA & \multirow{3}{*}{ mRFP::Tcyc1Sc } & \multirow{2}{*}{$\mathrm{H}$} & \multirow{2}{*}{891 bp } & promoter-R \\
\hline mRFP-R & ATTAAACCTUCTTCGAGCGTCCCAAAACCTTC & & & & B1-F \\
\hline mRFPf-R & AGCGCGAGUCTTCGAGCGTCCCAAAACCTTC & & $\mathrm{H}$ & $891 \mathrm{bp}$ & HRS2f-F \\
\hline mRFPft-R & ATGGCGCCGGUGGAGTGGCGG & mRFP & $\mathrm{H}$ & 675 & HRS3f-F \\
\hline $\begin{array}{l}\text { Figure } 2 \text { Prim } \\
\text { fragments. } P C \\
\text { Center), } D=p A \\
\text { plasmids derive }\end{array}$ & $\begin{array}{l}\text { er sequences for amplifying the different USER-Br } \\
\text { 2 templates: } A=p A g 1-H 3, p R F-H U 2[15], B=p P K 2 \text { or } p \\
\text { N7-1 [18], E = pSM334 [19], F=pBARKS1 [20], G = A. ni } \\
\text { d from the original Discosoma sp. study [22]. In prime }\end{array}$ & $\begin{array}{l}\text { ks, specifying templa } \\
\text { ZP-201BK }[16], C=\text { PAN } \\
\text { ulans genomic DNA or } \\
\text { sequences: } U=2 \text {-deox }\end{array}$ & $\begin{array}{l}\text { roduct } \\
g(R)[17 \\
H U E, p R \\
\text { ine. }\end{array}$ & $\begin{array}{l}\text { size and } \\
\text { 7] or pCSN4 } \\
\text { FF-HU2E }[15\end{array}$ & $\begin{array}{l}\text { compatible USER-Brick } \\
43 \text { (Fungal Genetics Stock } \\
5], \mathrm{H}=\text { pWJ1350 [21] or }\end{array}$ \\
\hline
\end{tabular}

analysed by colony-PCR, using the gene specific primers, and restriction enzyme digestion to verify correct assembly. In cases where the plasmids did not yield the expected results, the presence of the core USER-Bricks was tested by PCR.

The seven different types of vector constructs that the USER-Brick system currently allows for are shown in Figures 4 and 5 , including information on which fragments should be combined in the individual case. Additional file 1: Table S1 summarizes the USER Bricks needed for the different constructions. These can either be constructed using the pAg1-H3/pRF-HU2 (B1 + B2) or the ppPK2/pPZP-201BK (B3 + B4) vector backbones, but note that the two vector backbone systems are not mixable. For the construction of 'targeted deletion' vectors, exemplified with the $\mathrm{B} 1+\mathrm{B} 2$ backbone, the following was combined: $\mathrm{B} 1+\mathrm{B} 2+\mathrm{HygR} 1+$ upstream homologous recombination sequence (HRS) + downstream HRS, where the two HRS surround the target (Figure $4 \mathrm{C}$ and Additional file 1: Table S2). For 'in locus overexpression' constructions: $\mathrm{B} 1+\mathrm{B} 2+\mathrm{HygR} 1+\operatorname{Pgpd} \mathrm{A}+$ upstream HRS + downstream HRS, where the downstream HRS includes the start of the gene to be overexpressed (Figure 4D and Additional file 1: Table S2). For overexpression of genes from a random locus in the recipient fungus genome, $\mathrm{B} 1+\mathrm{B} 2 \mathrm{e}+\mathrm{HygR} 1+\operatorname{Pgpd} \mathrm{A}+\mathrm{CDS}+$ promoter element were combined (Figure $4 \mathrm{~B}$ and Additional file 1: Table S3). Figure 4 also describes the construction of vectors for random ectopic expression using the gene's natural promoter (Figure 4A). Figure 5, shows the strategies 


\begin{tabular}{|l|l|l|l|}
\hline Purpose & Primer name & Sequence (5' to 3') & Compatible overhang \\
\hline$\square$ Deletion / in locus overexpression & HRS1-F [A] & AGGTCGTATU-GSP & B2-R \\
\hline Deletion / in locus overexpression & HRS1-R [A] & AGTATTGCGU-GSP & marker F \\
\hline Deletion & HRS2-F [B] & ATGACCTAGU-GSP & marker R \\
\hline Deletion & HRS2-R [B] & ATTAAACCTU-GSP & B1-F \\
\hline In locus and ectopic expression* & HRS3 or CDS-F [C] & AGGCTGTAU-GSP & promoter-R \\
\hline In locus and ectopic expression & HRS3 or CDS-R [C] & ATTAAACCTU-GSP & B1-F \\
\hline Transcription reporter & PromoterX-F & ATGACCTAGU-GSP & marker R \\
\hline Transcription reporter & PromoterX-R & AGGAGGCCAU-GSP & mRFP-F \\
\hline Expression from fixed locus & CDSf-R & AGCGCGAGU-GSP & HRS2f-F \\
\hline Expression from fixed locus & HRS2f-F & ACTCGCGCU-GSP & CDSf-R \\
\hline N'terminal mRFP tagging* & HRS3f-F & ACCGGCGCCAU-GSP & mRFtf-R \\
\hline
\end{tabular}

Figure 3 Primer overhangs that should be added to the $5^{\prime}$ end of the gene specific primers to allow for construction of the specified types of vector constructs. $A=$ natural promoter regions of the target gene; $B=$ the terminator region of the gene and $C$ : for in locus overexpression experiments the first $1500 \mathrm{bp}$ of the gene so that the AU in the forward primer (HRS3, CDS-F and HRS3f) is part of the start codon, and for ectopic expression experiments so that the entire coding sequence and terminator are amplified.

for expression from a predefined (fixed) locus in the genome (Figure 5A), transcriptional reporters from random (Figure 5C) and fixed loci (Figure 5B) and N'terminal mRFP tagging (Figure 5D). For experiments comparing the effect of the vector backbone a pPK2:: $\triangle F a P G L 1 /$ PKS3 plasmid was constructed (USER-Bricks: B3 + B4 + HygR1 + FaPKS3-U1/U2 + FaPKS3-U3/U4).

\section{Optimizing ATMT of $F$. avenaceum}

The effects of hygromycin B (Invivogen), geneticin/G418 (Invivogen) and DL-phosphinothricin/Basta (Life Science) on germination of $F$. avenaceum was tested with the purpose of identifying the minimal concentration that allowed efficient inhibition during ATMT experiments. Five different concentrations of the three antibiotics were tested, hygromycin B: 75, 100, 150, 200, $250 \mu \mathrm{g} / \mathrm{ml}$; geneticin: 150 , 200, 250, 300, $350 \mu \mathrm{g} / \mathrm{ml}$ and for DL-phosphinothricin (Basta $^{\mathrm{rm}}$ ) 200, 400, 600, 800, $1000 \mu \mathrm{g} / \mathrm{ml}$. Macroconidia were initially plated onto black filter papers on IMAS medium, incubated for 48 hours and then transferred to DFM medium with the specified selection regimes. Following 10 days of incubation at $26^{\circ} \mathrm{C}$ in darkness, the amount of mycelium on and beneath the filters was evaluated.

ATMT was optimized using the pAg1-H3/pRF-HU2 vector series in the A. tumefaciens LBA4404 strain background with respect to six parameters. In these experiments, unless otherwise specified, the A. tumefaciens strain was pre-induced with $200 \mu \mathrm{M}$ acetosyringone until $\mathrm{OD}_{600} 0.7$, mixed $1: 1$ with $5^{*} 10^{5}$ macroconidia per agar plate, co-cultured for 2 days at $28^{\circ} \mathrm{C}$. The following parameters were the subject of optimization: pre-induction of A. tumefaciens (+/- acetosyringone), acetosyringone concentration during co-culturing $(0,200$ and $500 \mu \mathrm{M})$, cocultivation time (24, 48, 72 and 96 hours), co-cultivation temperature $\left(24^{\circ} \mathrm{C}, 26^{\circ} \mathrm{C}\right.$ and $\left.28^{\circ} \mathrm{C}\right), F$. avenaceum inoculum $\left(8 \times 10^{4}, 2 \times 10^{5}, 5 \times 10^{5}\right.$ and $1 \times 10^{6}$ macroconidia/ agar plate). The optimization was performed with three biological replicates, each with ten technical replicates (plates). The average number of obtained transformants per $10^{6}$ used spores was compared using a two tailed Student's $T$-Test assuming unequal variances, performed in Microsoft Excel 2010. The pRF-HU2:: $\triangle F a P G L 1 / P K S 3$ plasmid, targeting the PKS3/PGL1 locus, was used for all experiments, if not otherwise stated. For testing geneticin and DL-phosphinothricin based selection markers pRFGU2:: $\triangle F a P G L 1 / P K S 3$ and pRF-BU2:: $\triangle F a P G L 1 / P K S 3$ plasmids were constructed.

Following optimization the system was used for performing targeted modification of thirteen different loci spread across the $F$. avenaceum genome and for random integration of 30 different overexpression constructs from random loci. In these experiments $A$. tumefaciens was grown to $\mathrm{OD}_{600}$ of 0.7 in LB media supplemented with kanamycin, co-cultivation was performed for 72 hours at $26^{\circ} \mathrm{C}$, using $2 \times 10^{5}$ macroconidia per plate, and selection with $150 \mu \mathrm{g} / \mathrm{ml}$ hygromycin B for six days.

\section{Targeted gene replacement in $F$. graminearum}

The gene targeting efficiency in $F$. graminearum was assessed by targeted integration into the PKS3/PGL1 (FGSG_17168) locus using a pRF-HU2:: $\triangle F g P G L 1 / P K S 3$ plasmid containing the hygromycin resistance marker (HygR1) flanked by two 1500 bp homologous recombination sequences amplified from the $F$. graminearum genome. The ATMT was performed as described in [23].

\section{PCR based genotyping of transformants from targeted genome modification experiments}

In the experiments aimed at comparing gene targeting efficiency at the PGL1/PKS3 locus in $F$. avenaceum and F. graminearum, $100 \mathrm{~F}$. avenaceum and $104 \mathrm{~F}$. graminearum transformants were randomly selected for PCR genotyping using four different primer pairs (described below). The targeting efficiency for the thirteen other 


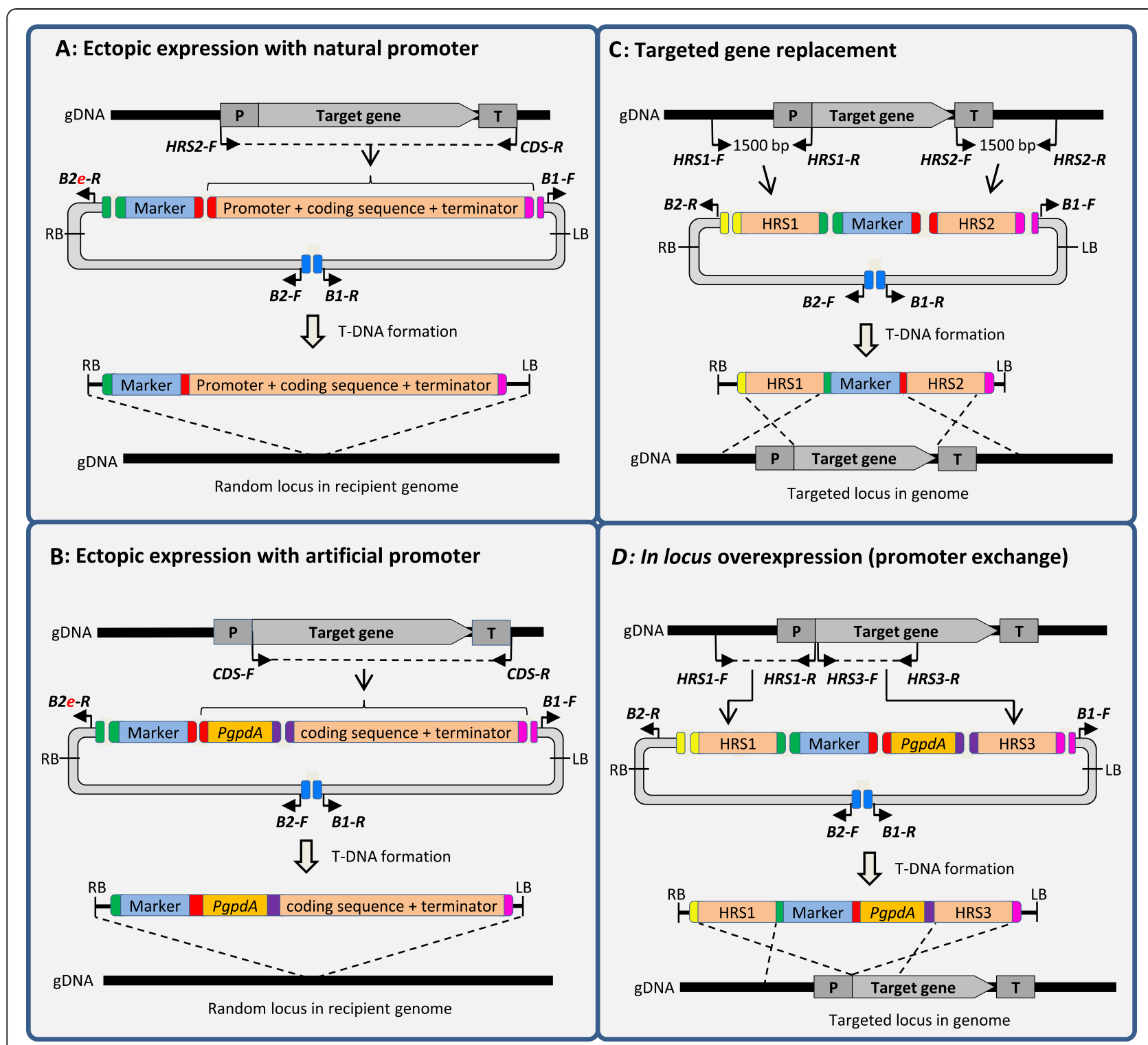

Figure 4 Design of vectors for random heterologous expression with the gene's natural promoter (A), with an alternative promoter (B), for targeted gene replacement (C) and in locus overexpression (D). A) Expression of the gene of interest from a random locus in the genome, driven by the gene's natural promoter. Note the use of the B2e USER-Brick to allow for direct fusion of the selection marker cassette with the B2 vector backbone. B) Overexpression of the gene of interest from a random genomic locus, with the expression driven by a heterologous promoter, in this case the gpdA promoter from Aspergillus nidulans. Note the use of the B2e USER-Brick to allow for direct fusion of the selection marker cassette with the B2 vector backbone. C) Replacement of the gene of interest. Note that the HRS1 fragment can also be reused for in locus overexpression experiments. D) In locus overexpression of the gene of interest by targeted integration of a strong constitutive promoter. Note that the HRS1 fragment can be reused for deletion experiments. Primers are represented by solid black arrows. Aberrations: gDNA = genomic DNA; $P=$ promoter; $C D S=$ coding sequence; $T$ = terminator; $R B$ \& $L B=$ right \& left borders defining the T-DNA region; T-DNA = transfer DNA.

targeted loci (deletions and in locus overexpression) in the $F$. avenaceum genome was determined by PCR genotyping of ten randomly selected transformants.

Genomic DNA for the study was obtained by transferring a small scrape of mycelium to a $1.5 \mathrm{ml}$ Eppendorf

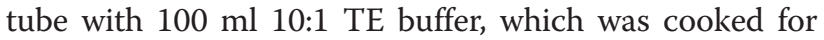
10 minutes in a 750 Watt microwave oven at full effect. The supernatant was then diluted 100 times with MilliQ water, and $1 \mu \mathrm{l}$ was used as a template in $15 \mu \mathrm{l}$ PCR reactions with the different test primers (Additional file 1: Table S4 and S5). The different transformants were initially tested using a primer pair targeting the introduced dominant selection marker, with the purpose of verifying that the diluted DNA was of PCR grade. For deletion constructs; a primer pair (T1/T2) amplifying an internal fragment of the gene that was targeted for replacement 


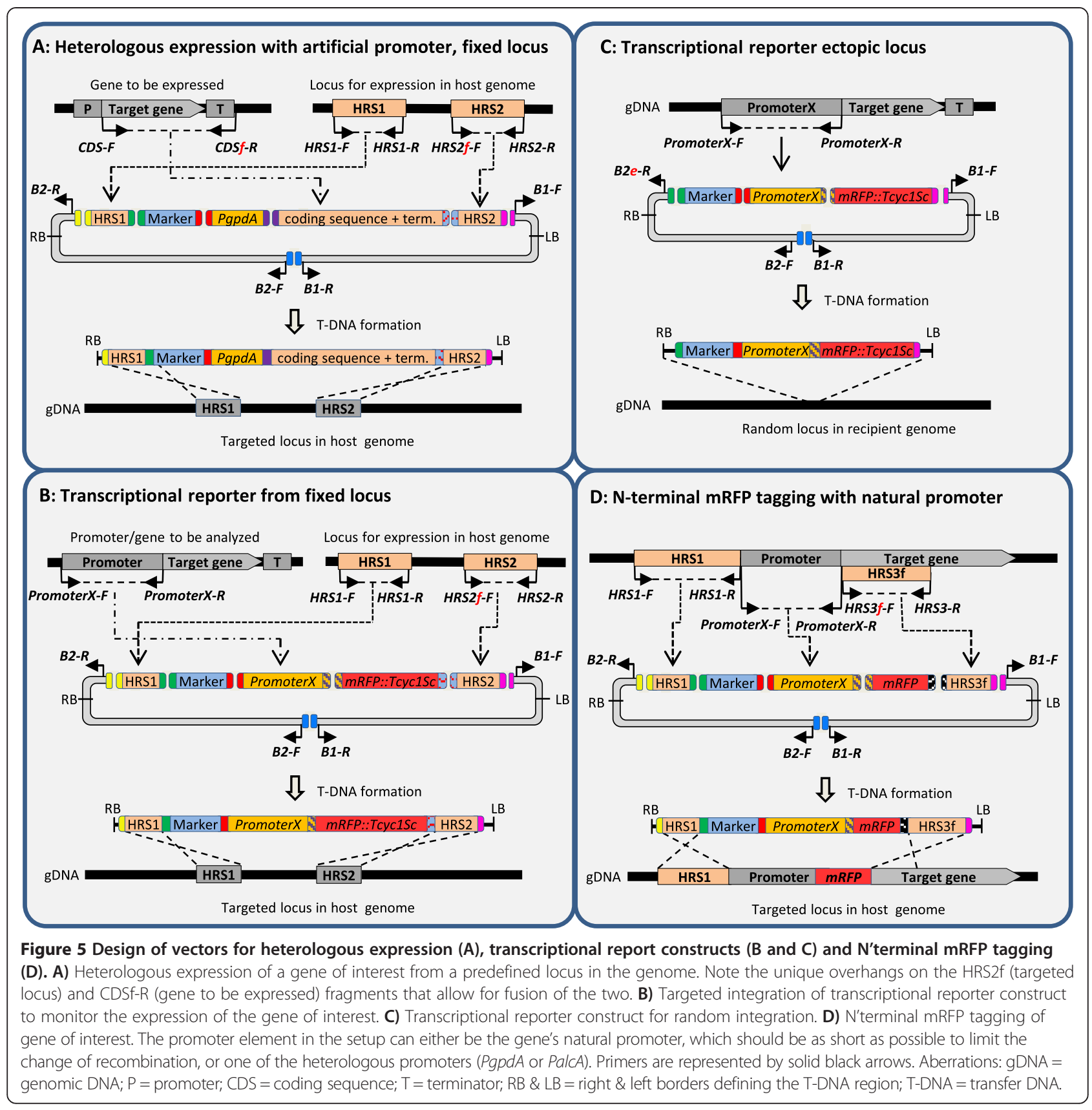

was then used, with the purpose of testing for gene replacement. For deletion and in locus constructs, two different primer pairs, each bridging one of the used targeting sequences (homologous recombination), were used to test whether homologous recombination had occurred. For deletions the RF-1/T3 and RF-2/T4 primers were used and for in locus the RF-3/T1 and RF-2/T2 primers were used (Additional file 1: Table S4). For ectopic expression constructs; two primer pairs (RF-3/T1 and T2/'PKS12-A4/A4-T1') were used to test for the presence of the start and end of the expression cassette (Additional file 1: Table S5). The PCR results were analysed by agarose gel electrophoresis (RunOne system, Embi Tec) or automated capillary electrophoresis (LabChip GX, PerkinElmer) (Table 1).

\section{Chemical analysis of the $\triangle F a P K S 6$ strains}

The wild type and three $\triangle F a P K S 6$ transformants, a class 2 and two class 3 (replacement), were grown in darkness for 9 days on YES medium at $28^{\circ} \mathrm{C}$. Following incubation the metabolites were extracted by means of the micro-scale method [24], using 3:2:1 (ethyl acetate/dichlormethane/ methanol $3 / 2 / 1$ with $1 \%$ formic acid). The samples were extracted for $1 \mathrm{~h}$ in an ultrasonic bath $\left(\right.$ Branson $^{\mathrm{TN}}$ Bransonic 
Table 1 Standard test primers for the analysis of the obtained transformants

\begin{tabular}{|c|c|c|c|}
\hline Primer name & Sequence $\left(5^{\prime}\right.$ to $\left.3^{\prime}\right)$ & Amplicon & Target \\
\hline \multicolumn{4}{|c|}{ Primers for testing of the selection markers } \\
\hline HygR-T-F & AGCTGCGCCGATGGTTTCTACAA & \multirow{2}{*}{$588 \mathrm{bp}$} & \multirow{6}{*}{ Test for marker gene } \\
\hline HygR-T-R & GCGCGTCTGCTGCTCCATACAA & & \\
\hline GenR-T-F & AGCCCATTCGCCGCCAAGTTCT & \multirow{2}{*}{$480 \mathrm{bp}$} & \\
\hline GenR-T-R & GCAGCTGTGCTCGACGTTGTCA & & \\
\hline BAR-T-F & TCAGATCTCGGTGACGGGCA & \multirow{2}{*}{$552 \mathrm{bp}$} & \\
\hline BAR-T-R & ATGAGCCCAGAACGACGCC & & \\
\hline \multicolumn{4}{|c|}{ Generic primers for testing targeted integration } \\
\hline RF-1 (HygR constructs) & 5'-AAATTITGTGCTCACCGCCTGGAC & * & T-DNA \\
\hline RF-2 (HygR constructs) & 5'-TCTCCTTGCATGCACCATTCCTTG & * & T-DNA \\
\hline RF-3 (PgpdA promoter) & 5'-TTGCGTCAGTCCAACATTTGTTGCCA & * & T-DNA \\
\hline RF-7 (GenR constructs) & $5^{\prime}$-CTTTGCGCCCTCCCACACAT & * & T-DNA \\
\hline RF-6 (GenR constructs) & 5'-TCAGACACTCTAGTTGTTGACCCCT & * & T-DNA \\
\hline RF-8 (BarR constructs) & $5^{\prime}$-CTGCACTITTATGCGGTCACACA & * & T-DNA \\
\hline RF-9 (BarR constructs) & 5'-CCTAGGCCACACCTCACCTTATTCT & * & T-DNA \\
\hline
\end{tabular}

The RF-1 to RF-9 primers anneal inside the different marker genes or introduced promoter and points out into the surrounding genome. These primers should be combined with primers annealing in the genome sequence surrounding the integration site. ${ }^{*}$ The size will depend on the primer design.

Ultrasonic Cleaner Model 2510), the organic phase was moved to new vials, and evaporated to dryness using $\mathrm{N}_{2}$. The samples were resuspended in $500 \mu \mathrm{l}$ HPLC grade methanol and ultrasonicated for $20 \mathrm{~min}$., filtered through a PFTE filter and analysed by Ultra high performance liquid chromatography-quadruple Time of Flight mass spectrometry (UHPLC-qTofMS).

UHPLC-qTOFMS analysis, of 0.3-2 $\mu \mathrm{L}$ extracts, was conducted on an Agilent 1290 UHPLC equipped with a photo diode array detector scanning 200-640 nm, and coupled to an Agilent 6550 qTOF (Santa Clara, CA, USA) equipped with an electrospray source (ESI). Separation was performed at $60^{\circ} \mathrm{C}$ and at a flow of $0.35 \mathrm{ml} /$ min on a $2.1 \mathrm{~mm}$ ID, $250 \mathrm{~mm}, 2.7 \mu \mathrm{m}$ Agilent Poroshell phenyl hexyl column using a water-acetonitrile gradient solvent system containing $20 \mathrm{mM}$ formic acid. The gradient started at $10 \%$ acetonitrile and was increased to $100 \%$ acetonitrile within $15 \mathrm{~min}$, keeping this for $4 \mathrm{~min}$, returning to $10 \%$ acetonitrile in $1 \mathrm{~min}$, and equilibrating for the next sample in $4 \mathrm{~min}$. Samples were analyzed in both $\mathrm{ESI}^{+}$and $\mathrm{ESI}^{-}$scanning m/z 50 to 1700 , and with automated data-dependent MS/MS on all major detected peaks, using collision energies of 10, 20 and $40 \mathrm{eV}$ for each MS/MS experiment. A MS/MS exclusion time of $0.04 \mathrm{~min}$ was used to get MS/MS of less abounded ions.

Data files were analysed in Masshunter 6.0 (Agilent technologies) in three different ways: i) Aggressive dereplication using lists of elemental composition and the Search by Formula (10 ppm mass accuracy) of all described Fusarium metabolites as well as restricted lists of only F. avenaceum and closely related species [25]; ii) Searching the acquired MS/MS spectra in an in-house database of approx. $1200 \mathrm{MS} / \mathrm{MS}$ spectra of fungal secondary metabolites acquired at 10, 20 and $40 \mathrm{eV}$ [26]; iii) all major UV/Vis and peaks in the BPC chromatograms not assigned to compounds (and not present in the media blank samples) were then also registered. For absolute verification authentic reference standards were available from 130 Fusarium compounds and furthermore 100 have been tentatively identified based on original producing strains, UV/Vis, LogD and MS/MS [25,27].

\section{Results and discussion}

The USER-Brick vector construction system

The past decade has seen an overwhelming blossom of new cloning systems that allow for easy vector construction, including systems based on Gateway [28], InFusion/CloneEZ [29], LIC [30], Gibson assembly [31] and USER cloning. The Uracil Specific Excision Reagent (USER) cloning method dates back to 1991 [32], however, it was initially largely ignored due to the costs associated with synthesising 2-deoxyuridine containing primers and the lack of a proofreading DNA polymerase which would not stall when encountering uracil-containing DNA segments. The technique was revitalized by Nour-Eldin and co-workers [33] based on the identification of the 2deoxyuridine tolerant $\mathrm{Pfu} \mathrm{Cx}$ polymerase, and further developed into the restriction enzyme digestion free USER Fusion cloning strategy by Geu-Flores [34]. The great advantage of the USER Fusion strategy compared to classical USER cloning and old-fashioned type II restriction enzyme or nicking enzyme based cloning techniques, is that it allows for scarless fusion of multiple fragments in a single cloning step, and only relies on the presence of an A- 
$\mathrm{N}_{8-15}$ - $\mathrm{T}$ motif in the junctions (Geu-Flores et al. 2007). Complementary overhangs which allow for directional assembly of multiple fragments is obtained via unique $5^{\prime}$ overhangs on the used primers. The overhangs include a 2-deoxyuridine base which later can be excised and allow for the formation of sticky ends $[34,35]$.

In the past, several USER based vector systems that allow for the construction of vectors compatible with fungal transformations have been presented [15,36]. Although these systems are superior to standard cloning strategies, with respect to ease of experimental design and cloning efficiency, their Achilles heel has always been the dependency on restriction enzyme digestion and nicking of the recipient plasmid. This is due to the dependency of complete digestion of the recipient vector to eliminate false positives which will otherwise shroud the desired correct transformants.

The new USER-Brick system relies entirely on PCR based amplification of all vector elements, which eliminates the time usage, costs and problems associated with the enzymatic digestion of the recipient plasmid. The unique $5^{\prime}$ overhangs introduced into the ends of the individual USER-Bricks during the amplification step ensures directional assembly of all fragments based on standard base pairing rules. The efficacy of the system was tested by constructing 27 different vectors targeting 14 different loci in the genome of $F$. avenaceum and 30 vectors for overexpression of genes from random loci. PCR based testing of 9-10 transformants from each of the 57 constructed vectors, showed that the system displays an assembly fidelity of $97 \%+/-0.3$ when fusing up to six DNA fragments in a single reaction (Additional file 1: Table S6). In the 16 cases, app. 3\%, where the resulting targeted genome modification plasmids did not test positive for the two expected gene specific fragments subsequent PCR tests for the Core-USER bricks in all cases confirmed that they were present.

In the tested setup the gene specific fragments, amplified from genomic DNA, were gel purified to eliminate unspecific products and primer dimers. However, in experiments with up to five fragments unpurified DNA was found to be as efficient as purified DNA, if no unspecific products were detectable by gel electrophoresis. This was not the case for the core USER-Bricks where purification was found to be essential to eliminate the vector DNA that had served as templates for the PCR reactions, which otherwise produced a high rate of false positives.

The developed system provides a versatile toolbox that can easily be expanded with additional USER-Bricks, such as alternative selection marker cassettes, promoters and fluorescent reporters, if need be. Either by adding the $5^{\prime}$ overhangs specified in Figure 2 to new bricks with similar functionality as those already used in the system or by designing compatible overhangs for new bricks with novel functionalities.

\section{Initial ATMT of $F$. avenaceum}

The efficiency of ATMT is highly dependent on abiotic factors, such as media composition, temperature and incubation time, and the optimal transformation conditions are typically unique for the individual fungal species [37]. In the case of $F$. avenaceum no protocol for transformation or targeted genome modification had been established, why we set out to develop and optimize a protocol that would allow future analysis of this species via a reverse genetic approach.

To determine the minimum concentration of hygromycin, geneticin and DL-phosphinothricin that could be used in ATMT experiments with $F$. avenaceum, the ATMT process was mimicked without bacterial cells and the growth of the fungus was recorded. The lowest usable hygromycin B concentration was found to be between 75 and $100 \mu \mathrm{g} / \mathrm{ml}$, why the highest of these were used in subsequent transformation experiments. Similarly for geneticin and DL-phosphinothricin the minimum useful concentrations were found to be $300 \mu \mathrm{g} / \mathrm{ml}$ and $600 \mu \mathrm{g} / \mathrm{ml}$, respectively.

For the initial transformation experiment random integration of the T-DNA region with the hygromycin resistance cassette, from pRF-HU2, was attempted using ATMT conditions that have previously worked well for $F$. graminearum [12]. The experiments yielded an average transformation frequency of $14+/-5.1$ transformants per $10^{6} \mathrm{~F}$. avenaceum spores based on an experiment with five technical replicates. Encouraging results which showed that ATMT based transformation of $F$. avenaceum was possible but would require optimization to yield a useful genetic engineering tool.

\section{Optimization of ATMT for $F$. avenaceum Pre-induction of A. tumefaciens}

The transformation frequency in ATMT of fungi has previously been shown to be influenced by pre-culturing of the A. tumefaciens cells with acetosyringone to induce the virulence response of the bacterium. Examples include Coccidioides immitis [38] and Aspergillus awamori where as little as $6 \mathrm{~h}$ of pre-induction yielded a 10 times increase in the number of transformants [39]. However, the opposite negative effect has also been reported for Beauveria bassiana [40]. In the case of $F$. avenaceum pre-induction of the used A. tumefaciens strain, for 16 hours, did not result in a statistically significant higher number of colonies (Figure 6). Similar results have been reported for Aspergillus carbonarius [41] and Magnaporthe grisea [42]. Mullins and co-workers found that pre-induction was not essential for the success of ATMT in the case of Fusarium oxysporum, but that the transformation process was delayed compared to experiments including preinduction [43]. 
A

Optimization of ATMT of $F$. avenaceum

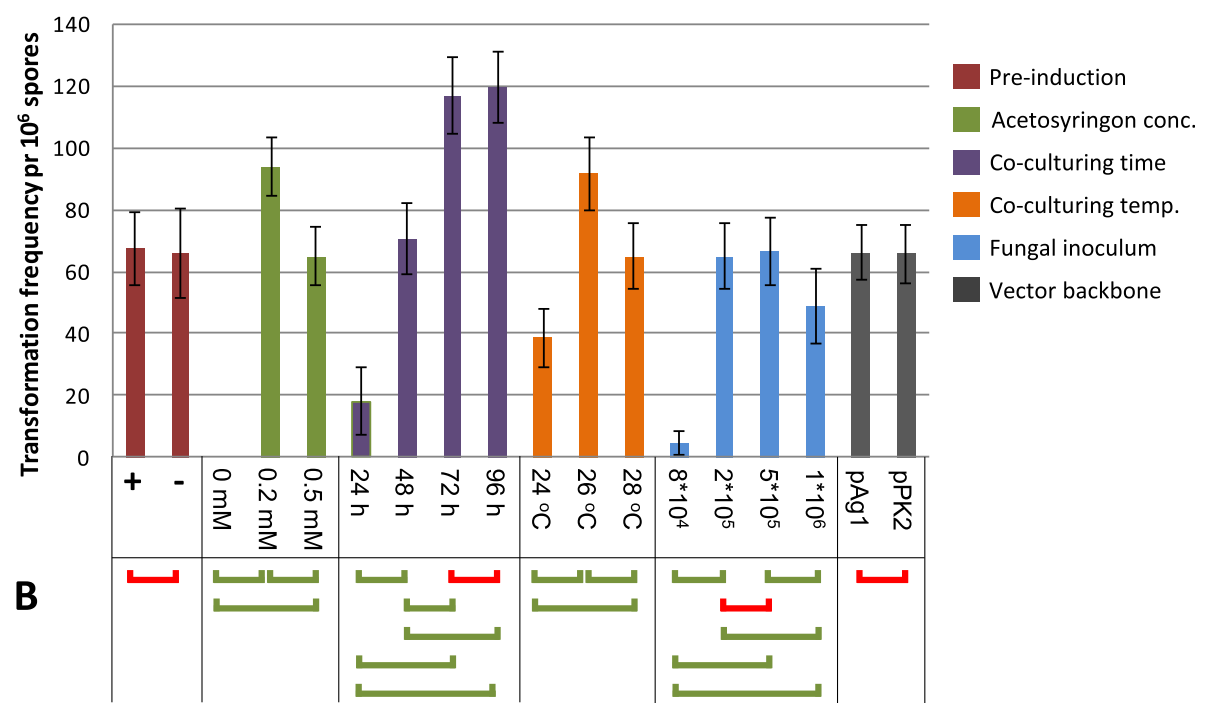

Figure 6 Results from optimization of the A. tumefaciens mediated transformation of $F$. avenaceum. A) The average number of transformants per $10^{6}$ spores obtained from three replicates which each included ten agar plates. B) Result from Student's T-Test comparing the different incubation conditions: green bars represent statistically significant different results for the two compared conditions, and red bars represent not statistically significant different results (further details can be found in the additional file).

\section{Acetosyringone concentration}

The presence of a bacterial virulence inducer, such as acetosyringone, during the co-cultivation period, was found to be essential for the successful transformation of $F$. avenaceum. An acetosyringone concentration of $200 \mu \mathrm{M}$ was found to give the highest number of transformants, while $500 \mu \mathrm{M}$ resulted in a significant reduction in the number of obtained transformants (Figure 6). This is in contrast to results for $B$. bassiana where an increase in the concentration in the range from $100 \mu \mathrm{M}$ to $800 \mu \mathrm{M}$ resulted in increasing numbers of transformants [44]. The observed reduction, for $F$. avenaceum, in the average number of obtained transformants with the higher inducer concentration has also been observed for Colletotrichum lagenarium where acetosyringone concentrations above $50 \mu \mathrm{M}$ resulted in a reduction in transformation frequency [45].

\section{Co-culturing time}

The co-culturing time was also found to impact the transformation frequency, and a significant increase was observed when the co-culturing time was prolonged from $24 \mathrm{~h}$ to $48 \mathrm{~h}$ and further to $72 \mathrm{~h}$ (Figure 6). Increasing it from $72 \mathrm{~h}$ to $96 \mathrm{~h}$ did not result in a statistically significant higher number of transformants, suggesting that the F. avenaceum mycelium is more susceptible to transformation within the first 72 hours or that the effects of the applied inducer was lost after this time point. A similar effect has been reported for Cryptococcus neoformans [46], while Michielse et al. 2004 found a decrease in the transformation frequency for $A$. awamori when extending the co-culturing time from $48 \mathrm{~h}$ to $72 \mathrm{~h}$ [47]. Compared to F. graminearum where the optimal co-culturing time is $48 \mathrm{~h}$, the maximum transformation efficiency for $F$. avenaceum is delayed which is possibly due to a slower germination and growth rate of the latter species, as described by Summerell and co-workers [48].

\section{Co-culturing temperature}

The temperature at which the co-cultivation was performed also significantly affected the transformation frequency. Incubation at $26^{\circ} \mathrm{C}$ gave the highest number of transformants while lower, and higher temperatures yielded significantly lower numbers of transformants (Figure 6). This effect has also been observed for other fungal species, such as the ascomycete Botrytis cinerea [49], the zygomycete Mortierella alpine [50] and the basidiomycete Hebeloma cylindrosporum [51]. In all cases, the authors have noted that the effect is linked to the optimal germination/growth temperature of the fungus that is being transformed.

\section{Fungal inoculum}

Quite interestingly the number of used macroconidia also impacted the number of obtained transformants significantly. The two medium concentrations tested yielded the same number of transformants, while an increase from $5 * 10^{5}$ to $1 * 10^{6}$ macroconidia per plate lead to a significant reduction (Figure 6). A similar reduction has been 
reported for Paecilomyces fumosoroseus [52]. The biological explanation for the reduction is possibly self-inhibition of germination at higher macroconidia concentrations, as described for other fungal species such as Colletotrichum fragariae [53]. The effect of the bacterial inoculum was not tested in the current study, and the concentration was kept constant at an $\mathrm{OD}_{600}$ of 0.7 at the stage of co-culturing for all experiments.

\section{Binary vector backbone}

In addition to the tested abiotic factors, several studies have also shown that the used vector backbone can affect the transformation efficiency. This was not seen for $F$. avenaceum when the two tested vector backbones, pAg1 and pPK2, yielded similar transformation frequencies (Figure 6).

\section{ATMT with optimized conditions}

The identified optimal conditions differed from the optimal conditions for transformation of F. graminearum by requiring a longer co-culturing time (increase from $48 \mathrm{~h}$ to $72 \mathrm{~h}$ ), lower co-culturing temperature (reduction from $28^{\circ} \mathrm{C}$ to $26^{\circ} \mathrm{C}$ ) and no pre-induction of $A$. tumefaciens. The identified optimal conditions were combined in a new ATMT protocol for $F$. avenaceum and used in a series of new transformation experiments, targeted modification of thirteen different loci, which yielded an average of 140 transformants per $10^{6}$ transformed spores. This shows that the contribution of the individual parameters to some extent are additive. However part of the expected gain was lost when the optimal conditions were combined, as one would expect the average transformation frequency to reach $\sim 160$ per $10^{6}$ spores based on the experiments where the individual parameters were manipulated. Targeted genome modification of the FaPKS3 locus using vectors with the geneticin and DL-phosphinothricin selection markers yielded similar transformation frequencies.

\section{Targeted genome modification in $F$. avenaceum versus} F. graminearum

To test the difference in targeted integration efficiency for $F$. avenaceum and F. graminearum, the orthologous
PKS3/PGL1 locus was chosen as the target. The PGL1 gene encodes a polyketide synthase that previously has been linked to the formation of the purple-black perithecial pigment of F. graminearum [54].

Following transformation, approximately 100 randomly selected transformants from each of the two species were genotyped by PCR. The analysis revealed a targeting efficiency of $85 \%$ in F. graminearum and $74 \%$ in F. avenaceum (Table 2). The targeting efficiency in other fungal species has been found to vary greatly, ranging from $0.04 \%$ for Blastomyces dermatitidis [55] to, the more frequently observed level, 29\% observed for Aspergillus awamori [39]. Members of the Fusarium genus in general display a high targeting efficiency, both when transformed by ATMT and protoplast based protocols [56].

Genotyping of the transformants from the experiments aimed at targeted deletion or overexpression of thirteen other loci in the F. avenaceum genome resulted in comparative targeting efficiencies (deletion: $72.1 \%$ and in locus overexpression: $81.9 \%$ ) as found for the PGL1/ PKS3 locus (Table 2 and Additional file 1: Table S7). However, surprisingly, in the twelve experiments aimed at in locus overexpression by insertion of a marker gene and promoter between the target gene's natural promoter and its start site, only ectopic (class 3) and double crossover (class 1) transformants were observed (Table 2 and Additional file 1: Table S7).

Random integration of T-DNA via non-homologous recombination (NHEJ) was more frequent in $F$. avenaceum $(10 \%)$ than in F. graminearum ( 1\%) (Table 2$)$. The low frequency of random integration in F. graminearum concurs well with previous reports by Malz et al. 2006, who found that ATMT based random mutagenesis of $F$. graminearum resulted in 50 times fewer transformants than observed for $F$. pseudograminearum [57]. In the thirty transformations (ectopic overexpression of TFs), which depended on integration via the NHEJ pathways in $F$. avenaceum, significantly fewer transformants were obtained $\left(25+/-3\right.$ per $10^{6}$ spores) compared to the number of transformants obtained in the above discussed experiments $\left(140\right.$ per $\left.10^{6}\right)$, which depended on HR integrations. This difference is likely

Table 2 Results from PCR based genotyping of targeted integration into $F$. graminearum and $F$. avenaceum

\begin{tabular}{lccccc}
\hline & No. tested & Class 1 (NHEJ/NHEJ) & Class 2 (NHEJ/HR) & Class 3 (HR/HR) & Gene targeting efficiency (\%) \\
\hline F. graminearum PKS3 & 104 & 1 & 15 & 16 & 88 \\
F. avenaceum PKS3 & 100 & 10 & & & $74.6 \%$ \\
$\begin{array}{l}\text { Other loci in F. avenaceum } \\
\quad \text { Deletion of 13 PKSs }\end{array}$ & 129 & 13 & 23 & 93 & $74.0 \%$ \\
$\quad$ In locus overexpression 12 PKSs & 116 & 20 & 1 & 95 & $81.9 \%$
\end{tabular}

$\mathrm{NHEJ}=$ non-homologous end joining; $\mathrm{HR}=$ homologous recombination. Class 1 transformants represent random integration events; Class 2 represents transformants where the T-DNA has integration by HR at one end and via an unknown mechanism at the opposite end (likely NHEJ); Class 3 transformants represent the desired gene targeting event where both ends have integrated by HR. The number for 'other loci' in $F$. avenaceum represents the average for all 13 deletions and 12 in locus overexpression experiments; see Additional file 1: Table S7 for results for the individual locus. 


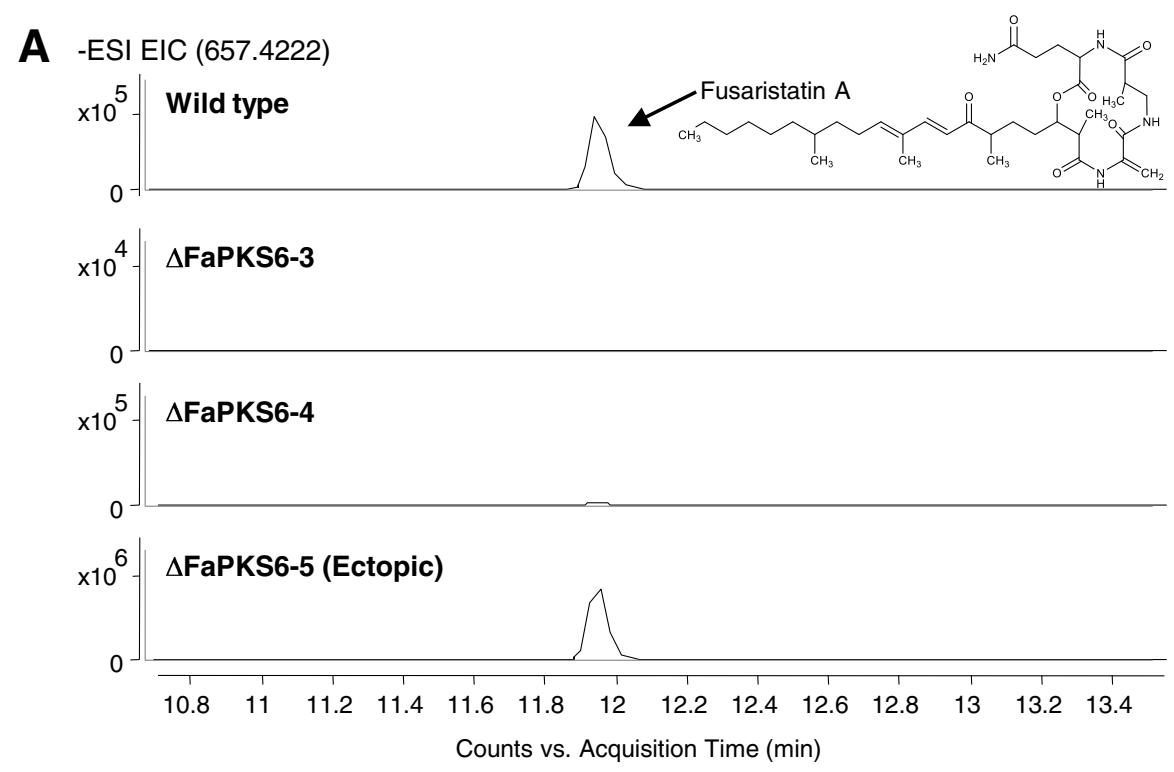

B $\times 10^{5}$

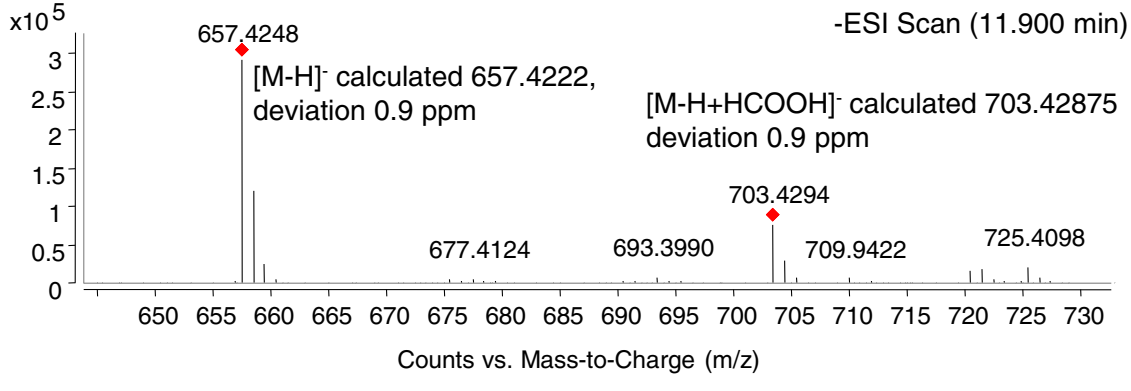

C $\quad$-ESI Product lon (11.938 min) Frag=365.0V CID @20.0 (657.4297[z=1] $\left.>^{* *}\right)$
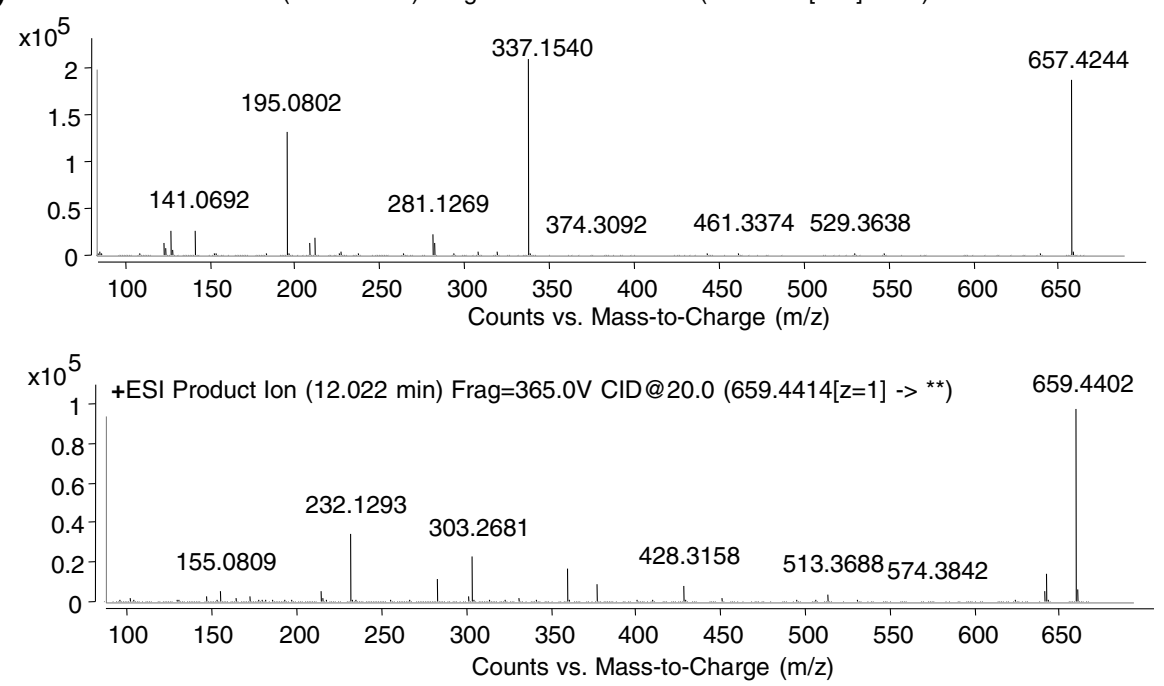

Figure 7 Linking of FaPKS6 to the formation of fusaristatin A. A) Extracted ion chromatogram, at 657.4222 Scan Frag $=365.0$ V, for the wild type and three $\triangle F a P K S 6$ transformants grown on YES medium. The two confirmed PKS6 replacement strains T3 and T4 have lost the ability to produce fusaristatin A whereas the $\triangle F a P K S 6-T 5$ strain (failed replacement) retains the ability. B) Mass spectrum (m/z plot) for the peak at 11.949 minutes and identification of the molecular ion $[\mathrm{M}-\mathrm{H}]^{-} 657.4248$ and $[\mathrm{M}-\mathrm{H}+\mathrm{HCOOH}]^{-} 703.4294$ adduct. C) MS/MS based fragmentation in negative and positive mode, using a CID of $20.0 \mathrm{eV}$ : Top panel shows fragmentation of the $[\mathrm{M}-\mathrm{H}]^{-}$mass ion and the bottom panel shows fragmentation of the $[\mathrm{M}+\mathrm{H}]^{+}$ion. 
due to the fact that integration via the homologous recombination (HR) pathway is not an option due to the lack of homologous recombination sequences in the introduced T-DNA. This supports the initial findings that experimental strategies relying on random mutagenesis by ATMT is feasible in F. avenaceum, which is not the case in F. graminearum. PCR based genotyping of the obtained transformants showed that $85 \%$ (average for all thirty experiments) tested positive for both ends of the TF expression cassette, while 15\% showed various levels of truncation (Additional file 1: Table S8).

\section{Linking of FaPKS6 to production of fusaristatin A}

To show that the developed molecular toolkit, USERBrick system and ATMT of F. avenaceum, can be used for functional characterization of genes, we analysed the impact on production of secondary metabolites in the constructed FaPKS6 deletion strain.

Chemical profiling of the $\triangle F a P K S 6$ strains compared to the wild type, by UHPLC-qTOFMS, showed that the deletion strain had lost the ability to produce a compound with a retention time of $\sim 11.9$ min compared to the wild type (Figure 7A, A). Based on the identification of the $[\mathrm{M}-\mathrm{H}]^{-}$ and $[\mathrm{M}+\mathrm{HCOO}]^{-}$adducts from $\mathrm{ESI}^{-}$and the $[\mathrm{M}+\mathrm{H}]^{+}$ and $[\mathrm{M}+\mathrm{Na}]^{+}$from $\mathrm{ESI}^{+}$elemental compositions could be unambiguously assigned as $\mathrm{C}_{36} \mathrm{H}_{58} \mathrm{~N}_{4} \mathrm{O}_{7}$. The elemental composition was searched in Antibase2012 [27] and an inhouse database [25] showing only one compound with this elemental composition, fusaristatin A (Figure 7A). With the UV/Vis spectrum not providing any structural information, the dereplication was, besides the elemental composition, based on: i) retention time, where fusaristatin A elutes very close to the enniatins (available as reference standards); ii) and MS/HRMS where ammonia was lost in $\mathrm{ESI}^{+}$, which is a distinct feature of primary amides (Figure $7 \mathrm{C}$ ) also the $\mathrm{ESI}^{-} \mathrm{MS} / \mathrm{MS}$ spectrum showed $\mathrm{m} / \mathrm{z} 529.3638$ which is consistent with loss of glutamine and $\mathrm{m} / \mathrm{z} 337.1540$ with loss of the $\beta$-aminoisobutyric acid-glutamine and breakage partial loss of the fatty acid chain at the carbonyl bond. From $\mathrm{ESI}^{+} \mathrm{MS} / \mathrm{MS}$, the fragments $\mathrm{m} / \mathrm{z} 513.3688$ was consistent with loss of glutamine including the oxygen from the fatty acid moiety and $\mathrm{m} / \mathrm{z} 428.3158$ with loss of $\beta$ aminoisobutyric acid-glutamine including the oxygen from the fatty acid moiety. Finally, the compound was recently identified in the very closely related F. tricinctum [58]. Fusaristatin A was first isolated and characterized from the endophytic Fusarium sp. YG-45 strain [59], and has later also been identified in the endophyte Phomopsis longicolla [60].

The identification is further supported by the domain structure of FaPKS6, and other Fusarium PKS6 orthologs, which classifies it as a potential highly reducing PKS with a C-methyltransferase domain. FaPKS6 likely catalyses the formation of the partially reduced decaketide portion of fusaristatin A, which is decorated with three C-bound methyl groups. Following PKS synthesis of the decaketide, it is subsequently elongated by the addition of dehydroalanine, 3-aminoisobutyric acid and glutamine to the carboxylic acid end of the polyketide, likely catalysed by a nonribosomal peptide synthetase (NRPS). A possible candidate for this activity is FaNRPS7 (FA08708) which has three modules and is encoded by a gene located next to the FaPKS6 gene (FA08709).

This is the first time fusaristatin A has been reported in F. avenaceum and the first time its biosynthesis has been linked to a specific polyketide synthase.

Collectively, the linking of FaPKS6 to fusaristatin A in F. avenaceum shows that the developed USER-Brick system and ATMT protocol can be used for efficient functional characterization of genes in the F. avenaceum genome.

\section{Conclusion}

The USER-Brick strategy offers reduced experimental costs (no restriction enzymes), easier experimental design, quicker experimental flow, higher cloning efficiency, higher reproducibility between experiments and most importantly, flexibility in the design possibilities. Optimization of the ATMT protocol for F. avenaceum yielded an average transformation frequency of 140 transformants per $10^{6}$ spores in experiments aimed at targeted genome modification. In addition, the optimization process revealed that acetosyringone concentration, co-culturing time and temperature significantly impact the transformation frequency. Combined, the developed USER-Brick system and ATMT protocol offers a generous molecular toolbox that allows for efficient genome engineering in F. avenaceum and other filamentous fungi. In the current study, the system was used to successfully link the FaPKS6 gene to the biosynthesis of fusaristatin A.

\section{Additional file}

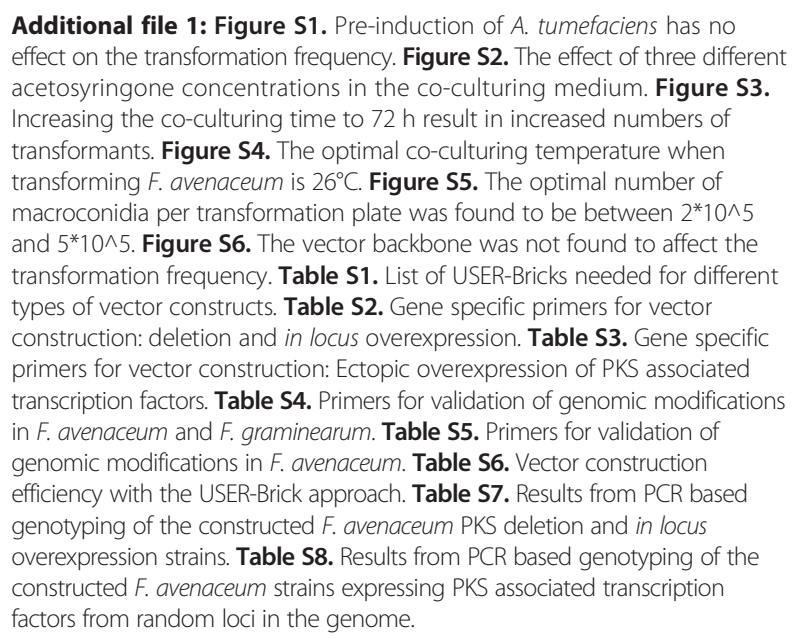




\section{Abbreviations}

ATMT: Agrobacterium tumefaciens mediated transformation; HR: Homologous recombination; NHEJ: Non-homologous end-joining; PCR: Polymerase chain reaction; PKS: Polyketide synthase encoding gene; T-DNA: Transfer DNA; USER: Uracil specific excision reaction.

\section{Competing interests}

The authors declare that they have no competing interests.

\section{Authors' contributions}

LQS and PKJ performed the transformation experiments aimed at targeted genome modification of FaPKSs encoding genes. JEL contributed with experiments aimed at ectopic overexpression of TF encoding genes. The metabolomics profiling and mass spectrometry based identification of Fusaristatin A was performed by KFN. RJNF conceived the study, developed the USER-Brick platform, optimized ATMT of F. avenaceum, wrote and edited the manuscript. All authors read and approved the final manuscript.

\section{Acknowledgements}

The research was funded by the 'Danish Research Council for Independent Research - Technology and Production' grant no. 09-069707 and a Young Elite Researcher grant no. 09-076147. We thank Agilent Technologies for the Thought Leader Donation of the 6550 QTOF instrument and UHPLC.

\section{Author details}

${ }^{1}$ Eukaryotic Molecular Cell Biology Group, Department of Systems Biology, The Technical University of Denmark, Søltofts Plads building 223, DK-2800 Kgs., Lyngby, Denmark. ${ }^{2}$ Metabolic Signaling and Regulation group, Department of Systems Biology, The Technical University of Denmark, Søltofts Plads building 221, DK-2800 Kgs., Lyngby, Denmark. ${ }^{3}$ BioforskNorwegian Institute of Agricultural and Environmental Research, Høgskoleveien 7, Ås 1430, Norway.

Received: 18 March 2014 Accepted: 4 July 2014

Published: 22 July 2014

\section{References}

1. Desjardins AE: Gibberella from $A$ (venaceae) to $Z$ (eae). Annu Rev Phytopathol 2003, 41:177-198.

2. Uhlig S, Jestoi M, Parikka P: Fusarium avenaceum - the North European situation. Int J Food Microbiol 2007, 119:17-24

3. Peters Rick D, Barasubiye Tharcisse DJ: Dry rot of rutabaga caused by Fusarium avenaceum. Hortoscience 2007, 42:737-739.

4. Sørensen JL, Phipps RK, Nielsen KF, Schroers H-J, Frank J, Thrane U: Analysis of Fusarium avenaceum metabolites produced during wet apple core rot. J Agric Food Chem 2009, 57:1632-1639.

5. Mercier J, Markhlouf JMR: Fusarium avenaceum, a pathogen of stored broccoli. Can Plant Dis Surv 1991, 71:161-162.

6. Aprasad KS, Bateman GL, Read PJ: Variation in pathogenicity on potato tubers and sensitivity to thiabendazole of the dry rot fungus Fusarium avenaceum. Potato Res 1997, 40(4):357-365.

7. Kulik T, Pszczółkowska A, Łojko M: Multilocus Phylogenetics show high intraspecific variability within Fusarium avenaceum. Int J Mol Sci 2011, 12(9):5626-5640.

8. Sørensen JL, Giese $H$ : Influence of carbohydrates on secondary metabolism in Fusarium avenaceum. Toxins (Basel) 2013, 5:1655-1663.

9. Herrmann M, Zocher R, Haese A: Effect of disruption of the enniatin synthetase gene on the virulence of Fusarium avenaceum. Mol Plant Microbe Interact 1996, 9:226-232.

10. Frandsen RJN: A guide to binary vectors and strategies for targeted genome modification in fungi using Agrobacterium tumefaciens-mediated transformation. J Microbiol Methods 2011, 87(3):247-262.

11. Sambrook J, Fritsch EF, Maniatis T: Molecular Cloning: A Laboratory Manual. Cold Spring Harbor, NY: Cold Spring Harbor Laboratory Press; 1989:931-957.

12. Frandsen RJN, Frandsen M, Giese H: Targeted gene replacement in Fungal Pathogens via Agrobacterium tumefaciens-mediated transformation. Methods Mol Biol 2012, 835:17-45.

13. Yoder WT, Christianson LM: Species-specific primers resolve members of Fusarium section Fusarium. Taxonomic status of the edible "Quorn" fungus reevaluated. Fungal Genet Biol 1998, 23:68-80.
14. Nørholm MHH: A mutant Pfu DNA polymerase designed for advanced uracil-excision DNA engineering. BMC Biotechnol 2010, 10:21.

15. Frandsen RJN, Andersson JA, Kristensen MB, Giese H: Efficient four fragment cloning for the construction of vectors for targeted gene replacement in filamentous fungi. BMC Mol Biol 2008, 9:70.

16. Covert SF, Kapoor P, Lee M, Briley A, Nairn CJ: Agrobacterium tumefaciens-mediated transformation of Fusarium circinatum. Mycol Res 2001, 105(3):259-264.

17. Fulton TR, Ibrahim N, Losada MC, Grzegorski D, Tkacz JS: A melanin polyketide synthase (PKS) gene from Nodulisporium sp. that shows homology to the pks1 gene of Colletotrichum lagenarium. Mol Gen Genet 1999, 262:714-720.

18. Punt PJ, Oliver RP, Dingemanse MA, Pouwels PH, van den Hondel CA: Transformation of Aspergillus based on the hygromycin B resistance marker from Escherichia coli. Gene 1987, 56:117-124.

19. Flaherty JE, Pirttilä AM, Bluhm BH, Woloshuk CP: PAC1, a pH-regulatory gene from Fusarium verticillioides. Appl Environ Microbiol 2003, 69:5222-5227.

20. Pall ML, Brunelli JP: A series of six compact fungal transformation vectors containing polylinkers with multiple unique restriction sites. Fungal Genet Newsl 1993, 40:59-62.

21. Lisby M, Mortensen UH, Rothstein R: Colocalization of multiple DNA double-strand breaks at a single Rad52 repair centre. Nat Cell Biol 2003, 5:572-577.

22. Campbell RE, Tour O, Palmer AE, Steinbach PA, Baird GS, Zacharias DA, Tsien RY: A monomeric red fluorescent protein. Proc Natl Acad Sci U S A 2002, 99:7877-7882.

23. Frandsen RJN, Nielsen NJ, Maolanon N, Sørensen JC, Olsson S, Nielsen J, Giese H: The biosynthetic pathway for aurofusarin in Fusarium graminearum reveals a close link between the naphthoquinones and naphthopyrones. Mol Microbiol 2006, 61:1069-1080.

24. Smedsgaard J: Micro-scale extraction procedure for standardization screening of fungal metabolite production in cultures. $J$ Chromatogr $A$ 1997, 760:264-270.

25. Klitgaard A, Iversen A, Andersen MR, Larsen TO, Frisvad JC, Nielsen KF: Aggressive dereplication using UHPLC-DAD-QTOF: screening extracts for up to 3000 fungal secondary metabolites. Anal Bioanal Chem 2014, in press.

26. Broecker S, Herre S, Wüst B, Zweigenbaum J, Pragst F: Development and practical application of a library of CID accurate mass spectra of more than 2,500 toxic compounds for systematic toxicological analysis by LC-QTOFMS with data-dependent acquisition. Anal Bioanal Chem 2011, 400:101-117.

27. Nielsen KF, Månsson M, Rank C, Frisvad JC, Larsen TO: Dereplication of microbial natural products by LC-DAD-TOFMS. J Nat Prod 2011, 74:2338-2348.

28. Gardiner DM, Jarvis RS, Howlett BJ: The ABC transporter gene in the sirodesmin biosynthetic gene cluster of Leptosphaeria maculans is not essential for sirodesmin production but facilitates self-protection. Fungal Genet Biol 2005, 42:257-263.

29. Sleight SC, Bartley BA, Lieviant JA, Sauro HM: In-Fusion BioBrick assembly and re-engineering. Nucleic Acids Res 2010, 38:2624-2636.

30. Aslanidis C, de Jong PJ: Ligation-independent cloning of PCR products (LIC-PCR). Nucleic Acids Res 1990, 18:6069-6074.

31. Gibson DG, Young L, Chuang R-Y, Venter JC, Hutchison CA, Smith HO: Enzymatic assembly of DNA molecules up to several hundred kilobases. Nat Methods 2009, 6:343-345.

32. Nisson PE, Rashtchian A, Watkins PC: Rapid and efficient cloning of Alu-PCR products using uracil DNA glycosylase. PCR Methods App/ 1991, 1:120-123.

33. Nour-Eldin HH, Hansen BG, Nørholm MHH, Jensen JK, Halkier BA: Advancing uracil-excision based cloning towards an ideal technique for cloning PCR fragments. Nucleic Acids Res 2006, 34:e122.

34. Geu-Flores F, Nour-Eldin HH, Nielsen MT, Halkier BA: USER fusion: a rapid and efficient method for simultaneous fusion and cloning of multiple PCR products. Nucleic Acids Res 2007, 35:e55.

35. Olsen LR, Hansen NB, Bonde MT, Genee HJ, Holm DK, Carlsen S, Hansen BG, Patil KR, Mortensen UH, Wernersson R: PHUSER (Primer Help for USER): a novel tool for USER fusion primer design. Nucleic Acids Res 2011, 39(Suppl 2):W61-W67.

36. Hansen BG, Salomonsen B, Nielsen MT, Nielsen JB, Hansen NB, Nielsen KF, Regueira TB, Nielsen J, Patil KR, Mortensen UH: Versatile enzyme expression and characterization system for Aspergillus nidulans, with the Penicillium brevicompactum polyketide synthase gene from the mycophenolic acid gene cluster as a test case. Appl Environ Microbiol 2011, 77:3044-3051. 
37. Michielse CB, Hooykaas PJJ, van den Hondel CAMJJ, Ram AFJ: Agrobacterium-mediated transformation as a tool for functional genomics in fungi. Curr Genet 2005, 48:1-17.

38. Abuodeh RO, Orbach MJ, Mandel MA, Das A, Galgiani JN: Genetic transformation of Coccidioides immitis facilitated by Agrobacterium tumefaciens. J Infect Dis 2000, 181:2106-2110.

39. Michielse CB, Ram AFJ, van den Hondel CAMJJ: The Aspergillus nidulans amdS gene as a marker for the identification of multicopy T-DNA integration events in Agrobacterium-mediated transformation of Aspergillus awamori. Curr Genet 2004, 45:399-403.

40. Leclerque A, Wan H, Abschütz A, Chen S, Mitina GV, Zimmermann G, Schairer HU: Agrobacterium-mediated insertional mutagenesis (AIM) of the entomopathogenic fungus Beauveria bassiana. Curr Genet 2004, 45:111-119.

41. Morioka LRI, Furlaneto MC, Bogas AC, Pompermayer P, Duarte RTD, Vieira MLC, Watanabe MAE, Fungaro MHP: Efficient genetic transformation system for the ochratoxigenic fungus Aspergillus carbonarius. Curr Microbiol 2006, 52:469-472.

42. Rho HS, Kang S, Lee YH: Agrobacterium tumefaciens-mediated transformation of the plant pathogenic fungus, Magnaporthe grisea. Mol Cells 2001, 12:407-411.

43. Mullins ED, Chen X, Romaine P, Raina R, Geiser DM, Kang S: Agrobacterium-mediated transformation of Fusarium oxysporum: An Efficient Tool for Insertional Mutagenesis and Gene Transfer. Phytopathology 2001, 91:173-180.

44. Fang W, Zhang Y, Yang X, Zheng X, Duan H, Li Y, Pei Y: Agrobacterium tumefaciens-mediated transformation of Beauveria bassiana using an herbicide resistance gene as a selection marker. J Invertebr Pathol 2004, 85:18-24.

45. Tsuji G, Fujii S, Fujihara N, Hirose C, Tsuge S, Shiraishi T, Kubo Y: Agrobacterium tumefaciens -mediated transformation for random insertional mutagenesis in Colletotrichum lagenarium. J Gen Plant Pathol 2003, 69:230-239.

46. McClelland CM, Chang YC, Kwon-Chung KJ: High frequency transformation of Cryptococcus neoformans and Cryptococcus gattii by Agrobacterium tumefaciens. Fungal Genet Biol 2005, 42:904-913.

47. Michielse CB, Ram AFJ, Hooykaas PJJ, van den Hondel CAMJJ: Role of bacterial virulence proteins in Agrobacterium-mediated transformation of Aspergillus awamori. Fungal Genet Biol 2004, 41:571-578.

48. Leslie JF, Summerell BA: The Fusarium Laboratory Manual. Ames IA, US: Blackwell Publishing; 2006. 132 and 176

49. Rolland S, Jobic C, Fèvre M, Bruel C: Agrobacterium-mediated transformation of Botrytis cinerea, simple purification of monokaryotic transformants and rapid conidia-based identification of the transfer-DNA host genomic DNA flanking sequences. Curr Genet 2003, 44:164-171.

50. Ando A, Sumida Y, Negoro H, Suroto DA, Ogawa J, Sakuradani E, Shimizu S: Establishment of Agrobacterium tumefaciens-mediated transformation of an oleaginous fungus, Mortierella alpina 1S-4, and its application for eicosapentaenoic acid producer breeding. Appl Environ Microbiol 2009, 75:5529-5535

51. Combier J-P, Melayah D, Raffier C, Gay G, Marmeisse R: Agrobacterium tumefaciens-mediated transformation as a tool for insertional mutagenesis in the symbiotic ectomycorrhizal fungus Hebeloma cylindrosporum. FEMS Microbiol Lett 2003, 220:141-148.

52. Lima IGP, Duarte RTD, Furlaneto $L$, Baroni $C H$, Fungaro MHP, Furlaneto MC: Transformation of the entomopathogenic fungus Paecilomyces fumosoroseus with Agrobacterium tumefaciens. Lett Appl Microbiol 2006, 42:631-636.

53. Miyagawa $H$, Inoue M, Yamanaka $H$, Tsurushima Tetsu UT: Chemistry of Spore Germination Self-Inhibitors from the Plant Pathogenic Fungus Colletotrichum fragariae. In Agrochem Discov Chapter 6, Volume 774. Edited by Baker DR, Umetsu NK. Washington, DC: American Chemical Society; 2000:62-71 [ACS Symposium Series (Series editor)].

54. Gaffoor I, Brown DW, Plattner R, Proctor RH, Qi W, Trail F: Functional analysis of the polyketide synthase genes in the filamentous fungus Gibberella zeae (anamorph Fusarium graminearum). Eukaryot Cell 2005, 4:1926-1933.

55. Gauthier GM, Sullivan TD, Gallardo SS, Brandhorst TT, Vanden Wymelenberg AJ, Cuomo CA, Suen G, Currie CR, Klein BS: SREB, a GATA transcription factor that directs disparate fates in Blastomyces dermatitidis including morphogenesis and siderophore biosynthesis. PLOS Pathog 2010, 6:e1000846.
56. Duyvesteijn RGE, van Wijk R, Boer Y, Rep M, Cornelissen BJC, Haring MA: Frp1 is a Fusarium oxysporum F-box protein required for pathogenicity on tomato. Mol Microbiol 2005, 57:1051-1063.

57. Malz S, Grell MN, Thrane C, Maier FJ, Rosager P, Felk A, Albertsen KS, Salomon S, Bohn L, Schäfer W, Giese H: Identification of a gene cluster responsible for the biosynthesis of aurofusarin in the Fusarium graminearum species complex. Fungal Genet Biol 2005, 42:420-433.

58. Ola ARB, Thomy D, Lai D, Brötz-Oesterhelt H, Proksch P: Inducing secondary metabolite production by the endophytic fungus Fusarium tricinctum through coculture with Bacillus subtilis. J Nat Prod 2013, 76:2094-2099.

59. Shiono $Y$, Tsuchinari M, Shimanuki K, Miyajima T, Murayama T, Koseki T, Laatsch H, Funakoshi T, Takanami K, Suzuki K: Fusaristatins A and B, two new cyclic lipopeptides from an endophytic Fusarium sp. J Antibiot (Tokyo) 2007, 60:309-316.

60. Lim C, Kim J, Choi JN, Ponnusamy K, Jeon Y, Kim S-U, Kim JG, Lee C: Identification, fermentation, and bioactivity against Xanthomonas oryzae of antimicrobial metabolites isolated from Phomopsis longicolla S1B4. J Microbiol Biotechnol 2010, 20:494-500.

doi:10.1186/1471-2199-15-15

Cite this article as: Sørensen et al:: Genetic transformation of Fusarium avenaceum by Agrobacterium tumefaciens mediated transformation and the development of a USER-Brick vector construction system. BMC Molecular Biology 2014 15:15.

\section{Submit your next manuscript to BioMed Central and take full advantage of:}

- Convenient online submission

- Thorough peer review

- No space constraints or color figure charges

- Immediate publication on acceptance

- Inclusion in PubMed, CAS, Scopus and Google Scholar

- Research which is freely available for redistribution

Submit your manuscript at www.biomedcentral.com/submit
C) Biomed Central 